Market Integration, Efficiency, and Interconnectors:

The Irish Single Electricity Market

Rabindra Nepal and Tooraj Jamasb

July 2011

CWPE $1144 \& 1121$ 


\section{疄圈 UNIVERSITY OF \\ CAMBRIDGE \\ Electricity Policy \\ Research Group}

\section{Market Integration, Efficiency, and Interconnectors: The Irish Single Electricity Market}

EPRG Working Paper 1121

Cambridge Working Paper in Economics 1144

\section{Rabindra Nepal and Tooraj Jamasb}

Abstract

Interconnections can be an effective way to increase competition in wholesale electricity markets in particular for smaller markets with few actors. This paper quantitatively examines the potentials for interconnections in the Irish Single Electricity Market (SEM). We use a time-varying Kalman filter technique to assess the degree of market integration between SEM and other large, mature and interconnected wholesale electricity markets in Europe. The results indicate a low degree of market integration between SEM and other European markets and thereby raising the possibility to benefit from increased electricity trade. As wholesale prices in SEM remain relatively high and volatile; a larger interconnector capacity can promote competition, close the gap with the European wholesale prices, improve security of supply, and mitigate price volatility. The results indicate that wholesale spot trading of renewable may not increase market integration. The results suggest that an interconnector capacity amounting to about $21 \%$ of generation capacity in SEM is likely to achieve an integration coefficient of 0.86 similar to what currently exists between the markets in Austria and the Netherlands.

Keywords

Contact

Publication

Financial Support interconnection, wholesale markets, market integration, competition

rn71@hw.ac.uk

July, 2011

James-Watt/SML Scholarships, Heriot-Watt University

www.eprg.group.cam.ac.uk 


\section{愻圈 UNIVERSITY OF (1) CAMBRIDGE Electricity Policy Research Group}

JEL Classification

L94; C22; D02; G1 


\title{
Market Integration, Efficiency, and Interconnectors: The Irish Single Electricity Market
}

\author{
Rabindra Nepal \\ Department of Economics, Heriot-Watt University \\ Tooraj Jamasb \\ Department of Economics, Heriot-Watt University
}

\section{Introduction}

The establishment of a competitive wholesale electricity market is a priority for many electricity markets in Europe. The drive towards a competitive and common internal market for electricity has led to the creation of organized wholesale spot markets (power exchanges) and increased cross-border wholesale electricity trade across many European countries. While the European Union's Directive 2003/54/EC requires the member states to open the market and guarantee non-discriminatory network access to third-parties; the EU Directive 2009/72/EC places wider emphasis on cross borderinterconnections and the need to mitigate barriers to cross-border trade to meet its energy policy goals and targets of sustainability, affordability and security of supply.

Coinciding with the overall policy changes in the EU; the Northern Ireland Authority for Utility Regulation (NAIRU) and the Commissions for Energy Regulation (CER) have since November 1, 2007 started jointly regulating the all-island Single Electricity Market (SEM) encompassing both Northern Ireland and the Republic of Ireland. SEM as all-island small electricity market encompasses approximately 2.5 million electricity customers, 1.8 million in the Republic of Ireland and 0.7 million in Northern Ireland. As a centralised gross mandatory pool, all electricity in SEM is traded through a market clearing mechanism based on the generators bidding their Short Run Marginal Cost (SRMC) and receiving the System Marginal Price (SMP) ${ }^{1}$.

\footnotetext{
Acknowledgement: The authors would like to gratefully thank the Northern Ireland Utility Regulator of Electricity, Gas and Water (UREGNI) for their valuable collaboration and providing the necessary data and information in completing this study. We would also like to thank an anonymous referee for providing detailed comments in the earlier version of the paper.

${ }^{1}$ In addition, the power producers receive separate capacity payments based on available generation capacity and constraint payments for the difference between the market schedule and the system dispatch. Suppliers, on the other hand, purchase electricity from the pool by paying the SMP for each trading period along with capacity payments and system charges.
} 
Economic theory suggests that SRMC pricing is desirable to achieve Pareto efficient outcomes (i.e. allocative efficiency) by optimally allocating the scarce economic resources at a given time (Hotelling, 1939). However, the risk of societal welfare losses (deadweight losses) is high in SEM due to the dominance of the wholesale market by two large incumbent electricity groups on the island, namely Electricity Supply Board (ESB) and Viridian with potential ability to exercise market power ${ }^{2}$. A vertically integrated market structure (between transmission and generation) can create every incentive and opportunity for exclusionary behavior making the electricity market more susceptible towards market power abuse and exercise (Joskow, 2003). Additionally, the combination of economic non-storability of electricity, low short-run elasticity of demand, high sunk costs as entry barriers, and short-run capacity constraints can increase the risks of strategic behaviour and market power exercise by the participants. Theory also suggests that the abuse of market power can lead to productive inefficiency implying that electricity will be underproduced and will no longer be produced at the least possible average cost (Boiteaux, 1965).

The isolation of the island economy from continental Europe has resulted in just one interconnector link (the Moyle interconnector) connecting SEM with Britain amounting to almost $4.7 \%$ of total SEM generation capacity. The lack of an interconnected system can provide more opportunities for the incumbents to behave strategically and unilaterally profit from limited competition.

Interconnections are an effective way to increase competition in wholesale electricity markets in particular for smaller markets with limited number of participants. An interconnected system is economically justifiable because it incurs lower operating costs by permitting excess supply in one node to be utilized in other nodes where the marginal cost would be higher if there were no interconnection ${ }^{3}$ (Charun and

\footnotetext{
${ }^{2}$ Market power is the ability to profitably maintain prices above competitive levels by restricting output below competitive levels (Werden, 1996; Hogan, 1997). Vertical market power occurs when a single firm controls more than one component of electricity production while horizontal market power results due to the problems of concentration of ownership.

${ }^{3}$ Market coupling, for example, is a mechanism to interconnect markets with an overall aim of maximizing the total economic surplus of all participants involved across different power exchanges. Assuming sufficient transmission capacity, one exchange will export to another for as long as the marginal price offered in one is lower than the marginal bid price in the other, until the point that prices converge or available cross-border capacity is
} 
Morande, 1997). Hence, the total economic surplus is maximized as the most expensive energy is displaced. Likewise, an interconnected system provides potentials for capital costs reductions by incurring lower investments as it may no longer necessitate maintaining reserve generating capacity in every node in case of system failures (Turvey, 2006). It can even create incentives for optimizing the size and timing of new investments by associating with a more efficient system (Brunekreeft and Newberry, 2006). The theoretical analysis on the long run economics of interconnection suggests that interconnections will lead to an increase in consumer surplus and improved security of supply by increasing the total available capacity (Matsukawa and Mulder, 2004). Thus, the benefits of enhanced competition and cross border electricity price differences can potentially justify the economic logic of an interconnected market (Giesbertz and Mulder, 2008).

Economic studies on the theoretical and numerical models of strategic behaviour further indicate that it is more costly and hence less attractive to exploit market power in an interconnected market (Amundsen et al. 1998; Van Damme, 2004). Interconnecting fossil dominated electricity systems such as SEM with hydro based systems could reduce price volatility and mitigate subsequent market uncertainties (Matsukawa and Mulder, 2004). A stable wholesale price, on the other hand, provides stability to the wholesale market which can further help in providing appropriate investment incentives and market signals to the market participants (Green, 2008). An interconnected market should create opportunities to benefit from economies of scale as market size grows resulting in lower generation costs. In the absence of market power, the potential efficiency gains resulting from economies of scale should lead to lower wholesale prices. Hence, we expect that SEM can benefit through potential interconnections with other EU electricity markets in terms of enhanced competition, improved security of supply and lower electricity prices.

The aim of this paper is to primarily assess the current state of SEM and examine the possibilities and potentials to benefit from increased interconnections. For this purpose, we analyze the wholesale spot electricity price development of SEM with other large, mature and interconnected wholesale electricity markets in Europe using a

exhausted. In the EU, the trilateral market coupling between France, Netherlands and Belgium has proven to be largely successful since 2006. 
time-varying approach. We analyze the prices because they reflect all publicly available information while those prices instantly change to reflect new public information in an efficient market in line with the efficient market hypothesis (EMH) (Fama, 1970) ${ }^{4}$. As prices aggregate and reveal market information (Grossman, 1976); all identical goods must have only one price in an efficient (i.e. competitive and liquid) market (Burdett and Judd, 1883) ${ }^{5}$. Thus, an efficient market becomes fully integrated as 'an entire territory of which the parts are so united by the relations of unrestricted commerce that prices take the same level throughout with ease and rapidity' as defined by Cournot (Stigler, 1969) ${ }^{6}$. Market efficiency implies that the prices of homogenous products from diverse suppliers should follow same pattern over time in a fully integrated market.

However, none of the above discussed studies on electricity markets have analyzed the development of wholesale price in SEM while the occurrence of negative prices in the European Energy Exchange (EEX) ${ }^{7}$ and SEM possibly necessitates re-visiting the econometric methodology used in these existing studies. Negative prices occur in times of high power in feed (in particular from intermittent energy sources such as wind) which leads to a lower intersection of the merit-order curve with the demand function leading to lower wholesale power prices (Nicolosi, 2010). It is further believed that increased trade of renewable in the wholesale market will greatly improve the EU electricity market integration (Joseffson, 2009). Hence, we study the degree of market integration of SEM with other EU electricity markets using a dynamic approach to capture the subsequent effect of any structural and unobservable changes (such as political, economic, and regulatory) as revealed through prices over time. A low level of market integration would indicate the need for expanding

\footnotetext{
${ }^{4}$ According to efficient market hypothesis (EMH), markets can be weakly, semi-strongly or strongly efficient in terms of reflecting and processing information. Weak EMH claims that prices on trade already reflect all past publicly available information; semi-strong EMH claims both that prices reflect all publicly available information and that prices instantly change to reflect new public information while strong EMH additionally claims that prices instantly reflect even hidden or "insider" information (Fama,1970).

${ }^{5}$ This is also a definition of the Law of One Price (LOOP) which is difficult to achieve fully in electricity markets due to infrastructure bottlenecks such as limited transmission capacity. The law of one price states that in competitive markets free of transportation costs and barriers to trade, identical goods sold in different countries must sell for the same price when their prices are expressed in the same currency (Krugman and Obstfeld, 2003). See Engel and Rogers (2001) describing price convergence as the reduction in international price differentials while Lammont and Thaler (2003) provide some criticisms of LOOP.

${ }^{6}$ The concept of market integration was first defined by Cournot (Federico, 2007).

${ }^{7}$ The EEX allowed the possibility of energy prices in bids since September, 2008 as it closed with the negative prices for the first time in October, 2008.
} 
interconnections in SEM and benefit from price differences in international wholesale electricity markets.

The paper is organized as follows. Section 2 briefly discusses the relevant literature that analyses the wholesale electricity market integration in Europe. Section 3 describes the data and econometric methodology used in this study. The results are presented and discussed in Section 4. Section 5 concludes with relevant policy recommendations.

\section{Review of Relevant Literature}

Several studies have so far empirically examined the development of wholesale electricity prices across different European wholesale markets for varying time periods using econometric techniques. Bower (2002) compared day-ahead 2001 prices from the Nordic countries, the Netherlands, Germany, Spain and the UK applying correlation and cointegration analysis. The study found some evidence of an already integrated market especially among the Nordic countries, the Netherlands and Germany by 2001. Boisseleau (2004) used regression and correlation techniques based on the same dataset to determine the level of market integration and subsequently analyses the findings of Bower (2002). The findings indicated a low level of market integration among the European electricity markets. Armstrong and Galli (2005) examined the day-ahead price differentials between Spain, Germany, France and the Netherlands from 2002 to 2004 testing for price convergence. Their findings suggest a convergence of European electricity prices during this period.

However, Armstrong and Galli ignored the cross-border capacity allocation mechanisms. Based on this limitation, Turvey (2006) empirically studied the use of interconnectors and pricing of limited transmission capacities using correlation analysis. His findings based on the Anglo-French interconnector indicate a low correlation of flows and price differentials. A recent study by Zachmann (2008) analyses the integration of European electricity prices by studying the development of wholesale prices from 2002 to 2006 and includes congestion charges accounting for congestion and congestion management. The findings show that although bilateral price convergence occurred during 2002-2006, no single European electricity market 
exists so far. The study suggests that congestion charges cannot fully explain the low level of observed market integration using Kalman filter analysis.

As Kalman filter can even analyze time series not integrated of the same order; it is widely applied in other sectors of the economy as well. For example, Kradelogiou (1999) applied Kalman filter to analyze the agricultural markets in Bulgaria and Slovenia while Prazmoski (2005) used Kalman filter to study fiscal equilibrium in the Dominican Republic. Similarly, Neumann et al. (2006) applied Kalman filter to study market integration in the European natural gas markets while King and Cuc (1996); Cuddington and Wang (2004) used time-varying coefficients and autoregressive models of price differentials to examine the convergence of natural gas spot prices in USA. According to Bomhoff (1992), the coefficients estimate generated by the Kalman filter generally outperforms the coefficient estimate generated by Ordinary Least Squares (OLS) and is hence preferred to OLS. To the best of our knowledge, this paper is the first to study the price development of SEM with other large, mature and interconnected wholesale electricity markets in Europe using a state-space model based on the powerful recursive Kalman filter algorithm accounting for negative wholesale prices.

\section{Data and Econometric Methodology}

Bilateral wholesale electricity trading remains the dominant form of wholesale trade in some European countries ${ }^{8}$. However, electricity trade is no longer confined to overthe-counter (OTC) trade with the establishment of power exchanges in most European countries. A common market design across many power exchanges is the creation of a spot market in which electricity is traded for each hour of the day. Prices determined in the spot market can contain sufficient information on available generation capacity, supply flexibility, electricity demand levels and demand flexibility (Ulbig, 2010). Analyzing day-ahead prices can also avoid the temporal aggregation problems (see Hamilton, 1994) associated with using lower frequency data (such as monthly, yearly). Thus, we examine the development of hourly intraday prices in this paper.

Our dataset consists of wholesale spot prices from four countries in Continental Europe (Germany, the Netherlands, Belgium and Austria); Northern Europe (i.e. the

\footnotetext{
${ }^{8}$ In Germany, for example, 1900 TWh of wholesale electricity was traded bilaterally in the OTC market in 2005.
} 
Scandinavian countries) and the all-island Irish countries. All of these spot markets started operating before SEM while also being large and widely interconnected as shown in Table 1. Only 1\% of scheduled generation in SEM was obtained via the interconnector in 2008 (UREGNI, 2009). Figure one shows the scheduled generation mix for the first three quarters of 2009 (January-September). The fuel mix is dominated by gas fired generation constituting $69 \%$ followed by coal and wind at $9 \%$ and 7\% respectively. Spot trading of electricity in SEM is mandatory whereas other power exchanges represent low liquidity in comparison to SEM (especially EXAA and Belpex) as wholesale spot trading of electricity in these markets is voluntary while bulk electricity is being traded bilaterally in the OTC market.

Fig 1: Scheduled generation fuel mix

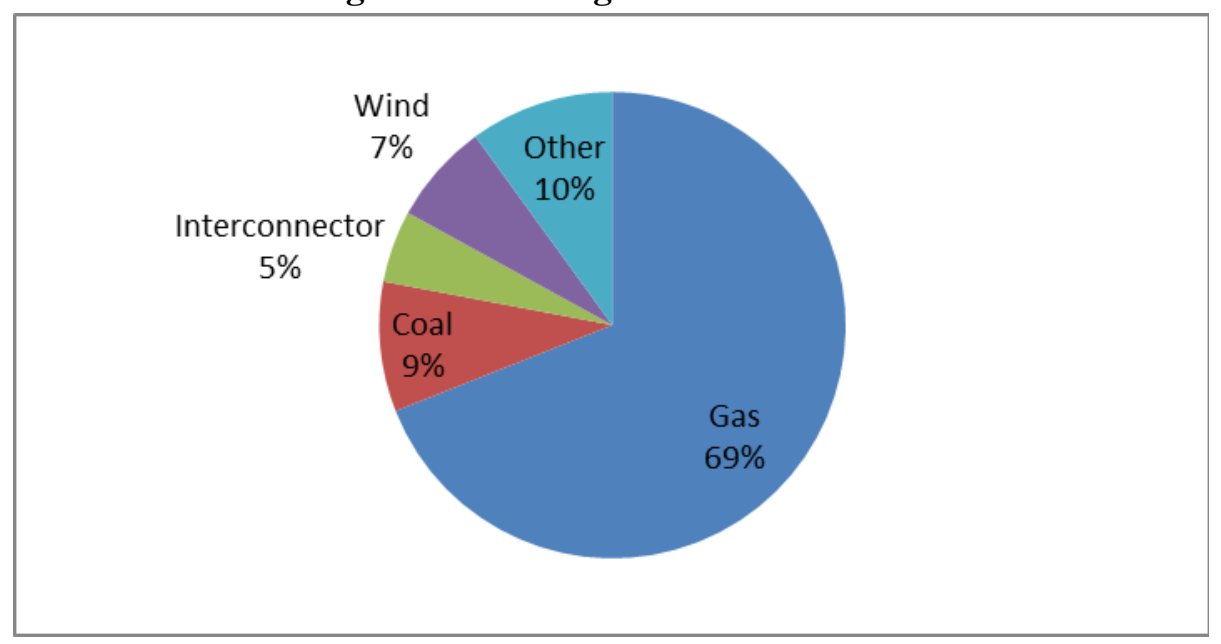

Source: UREGNI, 2009

However, a fundamental characteristic common across all power exchanges is the regulatory practice of day-ahead price setting based on 'sealed bid one-shot uniform price' auctions. The market operator (i.e. the auctioneer) collects all supply and demand bids while market clearing is done once per trading day separately for each hour (except for SEM where market clearing takes place every half-hour) and sold electricity is physically delivered the following day. Hence, all bidders essentially receive the same price (i.e. the SMP in our case) and any bidder who lowers his quantity offer can improve his terms of trade and the terms of trade of all winners (Klemperer, 2005). Despite minor differences in market structure and mechanisms, liquidity and products; the EXAA, EEX and APX operate in similar terms (Zachmann, 2008). 
The Scandinavian market which includes Denmark, Finland, Norway and Sweden has the largest joint spot market for electrical energy in the world called NordPool Spot that organizes a day-ahead spot market via Elspot. A spot market share of $72 \%$ indicates that Elspot is highly liquid. Similarly, EEX and SEM are the only power exchanges in our study with negative wholesale pricing regime in place. A negative spot price reveals the underlying opportunity costs (for example, avoided start-up and shut-down costs), gives higher value to consumer flexibility and provides additional price signal for storage of intermittent energy sources such as wind (Geneose et al., 2010). The possibility to trade with dual currencies in SEM makes it a unique organized market in the world.

Table 1: Characteristics of the Power Exchanges

\begin{tabular}{|c|c|c|c|c|c|c|}
\hline & Countries & Established & Currency & $\begin{array}{l}\text { Spot market } \\
\text { volume in } \\
2009 \text { (TWh) }\end{array}$ & $\begin{array}{c}\text { Total } \\
\text { Consumption in } \\
2009 \text { (TWh) }\end{array}$ & $\begin{array}{l}\text { Spot } \\
\text { market } \\
\text { share }\end{array}$ \\
\hline $\begin{array}{l}\text { European } \\
\text { Energy } \\
\text { Exchange } \\
\text { (EEX) }\end{array}$ & Germany & 2002 & EURO & 203 & 581 & $35 \%$ \\
\hline $\begin{array}{l}\text { Belgian } \\
\text { Power } \\
\text { Exchange } \\
\text { (BELPEX) }\end{array}$ & Belgium & 2006 & EURO & 10.1 & 81.7 & $12.4 \%$ \\
\hline $\begin{array}{c}\text { Energy } \\
\text { Exchange } \\
\text { Austria } \\
\text { (EXAA) }\end{array}$ & Austria & 2002 & EUR0 & 4.7 & 62.4 & $7.5 \%$ \\
\hline $\begin{array}{l}\text { Amsterdam } \\
\text { Power } \\
\text { Exchange } \\
\text { (APX) }\end{array}$ & Netherlands & 1999 & EURO & 29.1 & 122.8 & $23.7 \%$ \\
\hline $\begin{array}{l}\text { Nordpool } \\
\text { Power } \\
\text { Exchange } \\
\text { (ELSPOT) }\end{array}$ & Scandinavia & 2002 & NOK & 285.5 & 396.5 & $72 \%$ \\
\hline $\begin{array}{c}\text { Single } \\
\text { Electricity } \\
\text { Market } \\
\text { (SEM) }\end{array}$ & $\begin{array}{l}\text { Northern } \\
\text { Ireland and } \\
\text { Republic of } \\
\text { Ireland } \\
\end{array}$ & 2007 & $\begin{array}{c}\text { Euro and } \\
\text { Pound } \\
\text { Sterling }\end{array}$ & 34.6 & 36.2 & $95 \%$ \\
\hline
\end{tabular}

Source: Respective spot markets website

The time frame for hourly day-ahead prices ranges from 1 January 2008 to 6 January 2011 with the total number of observations surpassing 26,000 for all markets. The

\footnotetext{
${ }^{9}$ ELSPOT was registered as a separate company in 2002 after Denmark joined the pool. We do not consider the UK Power exchange as it is already connected to some extent to SEM via the Moyle interconnector. However, it would be interesting to study the effects of recent UK and the Netherlands interconnector (i.e. BritNed) on market outcomes in the future.
} 
data was obtained from publicly available sources for SEM data which was provided by the utility regulator. The hourly day-ahead prices data for SEM was constructed by averaging the half hourly prices within each hour. The descriptive statistics for the logarithmic transformed prices and non-logarithmic transformed prices (i.e. the raw prices) are presented and discussed.

Table 2 show the descriptive statistics of the logarithmic transformed day-ahead hourly wholesale prices across the power exchanges. Prices are logarithmic transformed as log prices can better reflect the underlying distribution of the residuals used in our model. Log transformed prices potentially mitigate the heteroscedastic properties of prices by minimizing the effects of high volatility and the outliers effects. The log wholesale prices in SEM are on average 4\% higher than APX and Belpex; 5\% higher than EEX and EXAA and 6\% higher than Elspot. The heavy use of gas in electricity generation coupled with (or) market power could have led to relatively higher wholesale prices in SEM though this remains to be empirically examined. The log-prices in SEM also remained the least volatile after Elspot possibly due to the exclusion of negatives prices resulting from excess energy supply from intermittent sources.

Table 2: Descriptive statistics (logarithmic transformed prices 2008-2011)

\begin{tabular}{|l|c|c|c|c|c|c|}
\hline & LAPX & LBELPEX & LEEX & LELSPOT & LEXAA & LSEM \\
\hline Mean & 1.659 & 1.656 & 1.643 & 1.624 & 1.640 & 1.722 \\
\hline Median & 1.672 & 1.679 & 1.663 & 1.632 & 1.663 & 1.714 \\
\hline Maximum & 2.698 & 3.384 & 2.693 & 2.477 & 2.394 & 2.842 \\
\hline Minimum & -2.000 & -2.000 & -2.000 & -1.698 & -2.000 & 0.517 \\
\hline Std. Dev. & 0.253 & 0.289 & 0.263 & 0.153 & 0.302 & 0.203 \\
\hline Skewness & -4.275 & -4.172 & -3.424 & -1.801 & -5.662 & 0.437 \\
\hline Kurtosis & 54.572 & 49.846 & 30.376 & 21.379 & 62.675 & 3.565 \\
\hline Observations & 26206 & 26196 & 26329 & 26442 & 26061 & 26446 \\
\hline
\end{tabular}

However, it completely ignores the available information incorporated in the negative prices. This is due to the fact that log of negative prices does not exist thus leading to available information being omitted for EEX and SEM prices. The descriptive statistics obtained from Table A (see Appendix) for the raw wholesale prices (i.e. including the negative prices) suggest that day-ahead hourly wholesale prices were on average 12\% higher than APX, 16\% higher than EEX and 25\% higher than Elspot. 
While the Elspot prices were the least volatile of all; the prices in SEM experienced greater volatility of all markets. The reason could be due to more uncertainties associated with gas prices as well as the underlying trading uncertainty in a new, immature but liquid market. Figure 2 illustrates a graphical representation of the raw prices while Figure $\mathrm{A}$ in the appendix is the graphical representation of the logarithmic transformed day-ahead hourly wholesale prices.

The figure indicates that the price series are potentially homoscedastic and mean stationary at levels though needs to be tested. Nonetheless, the degree of market integration to be examined through price convergence is not clear which the aim of this paper is. Moreover, changes in time-variant observed and unobserved factors such as fundamental market rules and regulations, new market designs and other institutional changes are the likely factors to change the strength of price relationships across markets implying that markets either move towards a greater level of integration or they tend to diverge from each other. Hence, the notion of market integration or separation can be analyzed by testing for the convergence or divergence of the day-ahead hourly prices across the different markets considered in this study.

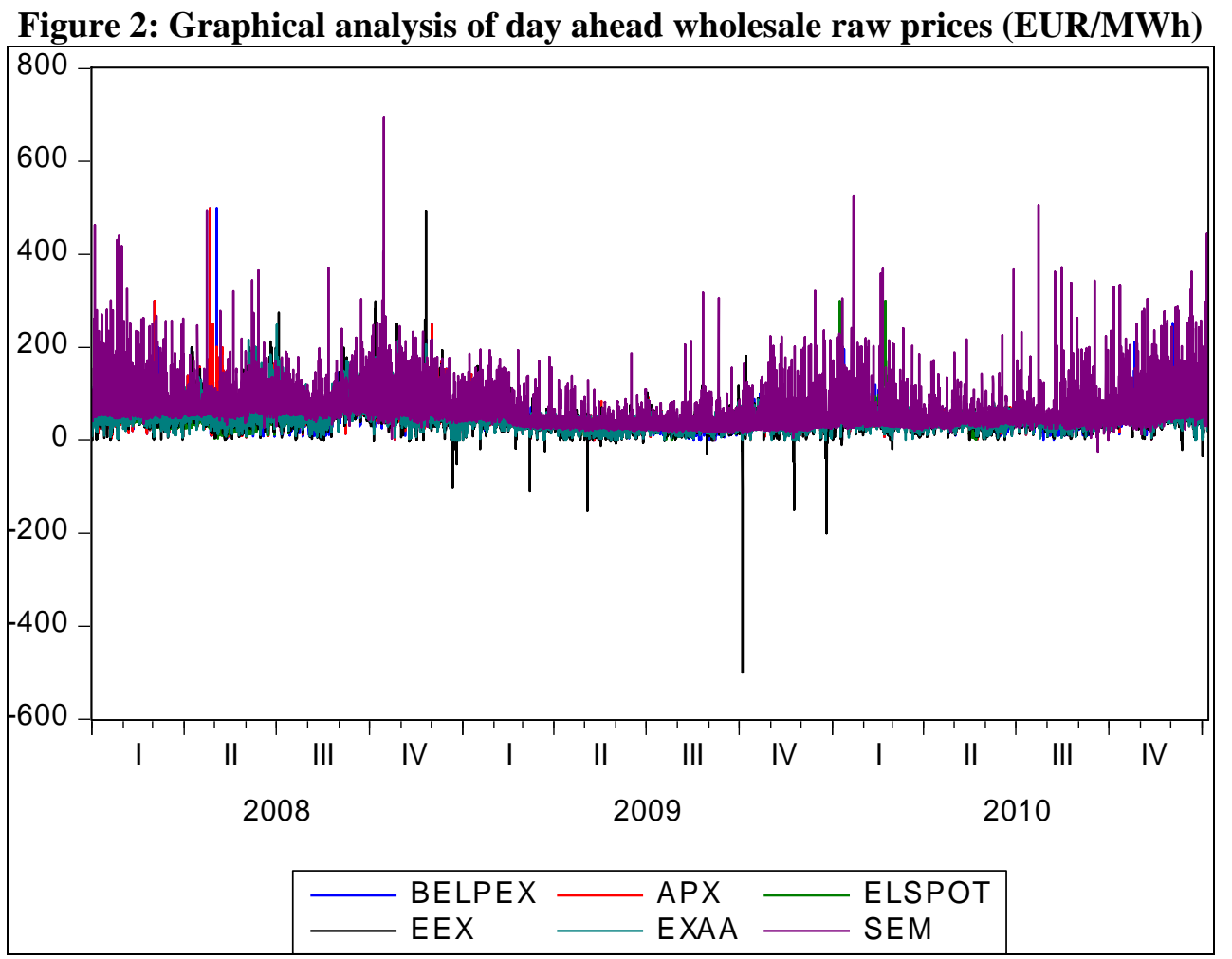


Although, cointegration analysis has been widely used to test for price convergence in the econometrics literature; one implicit assumption of cointegration analysis is that the structural relation among the prices is fixed over the considered time period. As mentioned in several studies including King and Cuc (1996) and Neumann et al. (2006); the cointegration analysis ignores the dynamics of any possible price convergence or divergence. Thus, considering the likely structural developments across all wholesale markets, the assumption of a fixed relationship between spot prices over time seems problematic.

Hence, we use a linear state space representation in order to examine the price convergence using Kalman filter analysis which is based on a recursive algorithm (Kalman, 1960). The state space approach incorporates the state variables (unobserved variables) to be estimated along with the observable model. With this approach, the nature and path of price convergence across markets can be studied, explaining market integration by estimating a time-variant coefficient model. Using the day-ahead hourly spot prices at SEM (Market A) and other large, mature and interconnected markets considered in this study (Market B), the following equations constituting a linear relationship between the two markets can be specified:

$$
\begin{aligned}
& \mathrm{P}_{\mathrm{A}, \mathrm{t}}=\alpha_{\mathrm{A}, \mathrm{B}}+\beta_{\mathrm{AB}, \mathrm{t}} \mathrm{P}_{\mathrm{B}, \mathrm{t}}+\varepsilon_{\mathrm{t}} \\
& \beta_{\mathrm{AB}, \mathrm{t}}=\beta_{\mathrm{AB}, \mathrm{t}-1}+\theta_{\mathrm{t}}
\end{aligned}
$$

where $\varepsilon_{t} \sim N$.i.i.d. $\left(0, \sigma_{\varepsilon}^{2}\right)$ and $\theta_{t} \sim N$.i.i.d. $\left(0, \sigma_{\theta}^{2}\right)$ are white noise processes.

Equation (1) is the 'signal' or 'observation' equation while equation (2) is the 'state' or transition equation. The state equation captures the effect of unobserved variables and incorporates those effects to be estimated with the observed model as represented by the signal equation. In the above set of equations, $\varepsilon_{\mathrm{t}}$ and $\theta_{\mathrm{t}}$ are normally and independently distributed random error terms (with zero mean and a normal variance $\sigma^{2}$ ) while $\alpha_{\mathrm{AB}}$ captures the time-invariant factors (such as the transactions costs, capacity charges, etc.) between the markets A and B. The vector of unobservable coefficients at any time $t$ is denoted by $\beta_{\mathrm{AB}, \mathrm{t}}$ which describes the price relationship between the two markets considered. Applying the time variant coefficient model to the price series $\left(\mathrm{P}_{\mathrm{A}}\right.$ and $\left.\mathrm{P}_{\mathrm{B}}\right)$ will enable us to identify the joint development of prices. It provides information on the value of state variables $\left(\alpha_{\mathrm{AB}}\right.$ and $\left.\beta_{\mathrm{AB}, t}\right)$ for each point in time for both price series. Therefore, the Kalman filter processes the data on both price series in two consecutive steps. It first estimates $\beta_{\mathrm{AB}, \mathrm{t}}$ by using available 
information till the period $t-1$. As a second step, the estimates of $\beta_{\mathrm{AB}, \mathrm{t}}$ are updated by incorporating prediction errors from the first step as information at time $t$ is realized. Thus, the Kalman filter is a recursive algorithm for subsequently updating (or error correcting) the one-step ahead estimate of the state mean and variance given new information.

In the process, the time variant coefficient model produces linear minimum mean error estimates of $\beta_{\mathrm{AB}, \mathrm{t}}$ using observed and available data through time t. Thus, being based on a specific optimization recursive algorithm it allows for the updating of the model estimations using newly available information (see Harvey, 1987; Hamilton, 1994). The filter approach ensures that the corrections made in $\beta_{\mathrm{AB}, \mathrm{t}}$ beyond $\mathrm{t}$ (say $\mathrm{t}+\mathrm{k}$ ) follow a time-varying moving average process of order $\mathrm{k}-1$.

Hence, if $A$ and $B$ spot markets are perfectly integrated, the value of $\beta_{A B, t}$ equals unity at any time $t$ implying conformity towards the law of one price. On the other hand, if $\beta_{\mathrm{AB}, \mathrm{t}}=0$ the prices of day-ahead hourly electricity traded on both markets bear no relation with each other at any time $t$ implying perfectly uncorrelated prices ${ }^{10}$. A full market integration indicates limited (or no) opportunity to benefit from cross border price differences through interconnections while a low market integration implies significant opportunities to benefit from differences in international electricity prices via cross border interconnections.

\section{Results and Discussions}

It is necessary to examine the properties and nature of those series as a pre-requisite for any econometric analysis of time series. Testing for unit roots is a well-established methodology in econometrics literature for such analysis involving time-series. Besides, empirical studies suggest that unit roots can also be used to test for pair-wise price convergence (or divergence) for price series (Aubyn, 1999; Bernard and Durlauf, 1996; Zachmann, 2008). However, the concept of applying unit roots to test for price convergence can be criticized on the grounds that the stationary property of price differences can mean both convergence and divergence while in the presence of

\footnotetext{
${ }^{10}$ If $\mathrm{A}$ and $\mathrm{B}$ hourly day-ahead markets are fully integrated or the spot prices are in full convergence, the value of $\left\{\lim _{\mathrm{t} \rightarrow \text { infinity }}\left(\mathrm{P}_{\mathrm{A}}-\mathrm{P}_{\mathrm{B}}\right)\right\}=\alpha_{\mathrm{AB}}$ while the final state of convergence shall be $\left\{\lim _{\mathrm{t} \rightarrow \text { infinity }} \beta_{\mathrm{AB}}\right\}=1$.
} 
outliers unit root tests can lack power and robustness. Though, it is not our aim to examine market integration via unit roots test, Table 3 reports the results from unit root tests based on Augmented Dickey-Fuller (ADF) test (Dickey and Fuller, 1979) and Kwiatkowski; Phillips; Schmidt and Shin (KPSS) test (KPSS, 1992) ${ }^{11}$.

Table 3: Unit root tests

\begin{tabular}{|c|c|c|}
\hline \multicolumn{2}{|c|}{ Electricity hourly day-ahead Prices (log) } \\
\hline \multirow{2}{*}{ Power Exchanges } & ADF & KPSS \\
\cline { 2 - 3 } & Level & Level \\
\hline APX & $-4.786^{* * *}$ & $0.358^{*}$ \\
\hline Belpex & $-7.607 * * *$ & 0.339 \\
\hline EEX & $-23.032^{* * *}$ & $0.353^{*}$ \\
\hline Elspot & $-2.253^{* *}$ & 0.313 \\
\hline EXAA & $-51.875^{* * *}$ & $0.423 *$ \\
\hline SEM & $-37.463^{* * *}$ & $0.375^{*}$ \\
\hline
\end{tabular}

Note: Tests include a constant but no time trend. For ADF, the lag length is selected according to Schwarz Information Criterion (SIC). For KPSS, bandwidth has been chosen according to Newey-West using the Bartlett Kernel. The numbers provided in the table denote the t-statistics for ADF and the LM statistic for KPSS.

$*, * *, * * *$ indicate significance at the 10,5 and $1 \%$-levels

The results suggest that the hourly day-ahead price series including the SEM are stationary at levels allowing us to assume that the first differences are also stationary in nature. Since electricity cannot be stored economically with demand having little or no effect (i.e. inelastic demand); the stationary behavior of hourly spot prices is expected. However, the absence of a unit root at levels also precludes the motivation to test for stable long run equilibrium relating between the price series. On the other hand, widely used cointegration technique such as Johansen test (Johansen 1998, 1991) assumes a constant cointegrating vector over time and thus not effectively allowing us to assess the development of market integration over time. The results from correlation analysis are economically misleading as it does not account for changes in the process of market integration (e.g. for short term price divergence) over-time. However, correlation analysis can be used to determine whether certain market pairs are integrated as the correlation coefficient provides a useful analysis on the initial level of market integration (Stigler and Sherwin, 1985). The correlation

\footnotetext{
${ }^{11}$ We present the results from both unit roots test as it is argued that the power of the KPSS test is high as compared to ADF while the results were similar for raw price series data as well though not presented here. Also, double testing improves the reliability of our results. However, ADF is based upon the null hypothesis of a unit root; the KPSS is based upon the null hypothesis of stationarity.
} 
results from Table 4 show the static notion of market integration between SEM and other large, mature and interconnected wholesale markets.

Table 4: Correlation results for logarithmic prices

\begin{tabular}{|c|c|c|c|c|c|c|}
\hline & LAPX & LBELPEX & LEEX & LELSPOT & LEXAA & LSEM \\
\hline LAPX & 1.000 & & & & & \\
\hline LBELPEX & 0.905 & 1.000 & & & & \\
\hline LEEX & 0.748 & 0.690 & 1.000 & & & \\
\hline LELSPOT & 0.438 & 0.410 & 0.420 & 1.000 & & \\
\hline LEXAA & 0.776 & 0.705 & 0.757 & 0.392 & 1.000 & \\
\hline LSEM & 0.619 & 0.562 & 0.538 & 0.304 & 0.562 & 1.000 \\
\hline
\end{tabular}

We can infer that the market integration of Elspot with other markets remains the lowest. SEM prices are thinly correlated with other spot markets with the price correlation for Elspot being the least. The lack of interconnection coupled with twin conditions of being a new market and differences in several institutional aspects such as market designs, regulatory framework, etc. can explain such low correlation. However, APX and Belpex markets are highly correlated as expected for reasons such as an already existing trilateral market coupling regime between France, Belgium and the Netherlands leading to increased international trade of electricity and harmonization of institutional framework. The correlation coefficients do not change much even after including the negative prices. Table $\mathrm{B}$ in Appendix shows the correlation coefficients of prices across the spot markets. The harmonization of market rules in terms of negative pricing regime between SEM and EEX improved the price correlation by around 5\%. Similarly, the price correlation between EXAA and EEX is also high due to high cross border electricity trade and the likely adoption of similar other wholesale market principles. The correlation results show some signs of bilateral convergence of prices among different market pairs.

The relatively low price correlations of SEM with other wholesale markets is sufficiently evident enough to indicate that significant potential exists to benefit from interconnections due to high differences in cross-border electricity prices. As such, although bilateral price convergence is possible among markets with high price correlations (APX-BELPEX, EEX-EXAA, APX-EXAA, etc.), the notion of a single European wholesale market for electricity is still far from being achieved. The 
persistence in international electricity price differences could be due to the scarcity in interconnector capacity. However, a recent study by Gebhardt and Hoffler (2010) argues that it is rather the lack of competition, a case where well-informed traders do not engage in international electricity trade, rather than the presence of limited interconnector capacities that explains the significant difference between international electricity prices. Nonetheless, it requires detailed empirical investigation that is beyond the scope of our paper.

Moreover, market integration is a dynamic process and can vary with time due to changes in economic and political environment in the national and international energy markets. Table 5 illustrates the strength of price relationship between SEM and other large, mature, and interconnected wholesale markets in Europe based on the Kalman filter using the Maximum Likelihood estimator.

Table 5: Market integration coefficients based on logarithmic prices

\begin{tabular}{|c|c|}
\hline \multicolumn{2}{|c|}{$\begin{array}{c}\text { Method: Maximum likelihood (Marquardt) } \\
\text { Sample: 1/01/2008 00:00 to 1/06/2011 23:00 }\end{array}$} \\
\hline Market Pairs & $0.12^{* *}$ \\
\hline SEM-EEX & $0.19^{* * *}$ \\
\hline SEM-APX & $0.18^{* * *}$ \\
\hline SEM-Belpex & $0.15^{* *}$ \\
\hline SEM-EXAA & $0.16^{* * *}$ \\
\hline SEM-Elspot & \\
\hline$* * * * * *$ indicate significance at the 10,5 and $1 \%-l e v e l s$ & \\
\hline
\end{tabular}

We can infer that the current (final) state of market integration of SEM is less than $20 \%$ with all other markets under consideration. The SEM prices are the least integrated with the EEX prices at $12 \%$ while integration with the APX market remains the highest at $19 \%$. The market coupling between the Netherlands and Belgium imply that the strength of price relationship between SEM and Belpex remains at $18 \%$. Similarly, the current level of market integration between the Austrian wholesale markets and the Nordic pool Elspot stands at 15\% and 16\% respectively. The low level of market integration between SEM and other European markets indeed provides strong indications to benefit from increased interconnections in the isolated SEM market. Hence, increasing cross border electricity trade via an interconnected system 
can be an important measure to improve market integration between the European wholesale electricity markets and SEM.

Although the isolation of SEM and thereby the lack of interconnection with other markets mostly explain the existing low level of market integration; several other factors are also significant. This is because market integration can be explained by a vector of factors such as the convergence of factor inputs (i.e. electricity) and final product prices; matching of institutional framework and electricity market regulation and the convergence of electricity consumption patterns coupled with similarity in generation technologies. However, the above results do not consider the incorporation of negative prices in wholesale market trade which is an important element of wholesale market design in EEX and SEEM. Thus, we also calculate the market integration coefficient based on the raw prices for the same market pairs as in Table 5 to better understand the role of renewable energy sources (primarily wind) wholesale electricity trade on wholesale market integration. The results are presented in Table 6.

Table 6: Market integration coefficients based on raw prices

\begin{tabular}{|c|c|}
\hline \multicolumn{2}{|c|}{ Method: Maximum likelihood (Marquardt) } \\
Sample: 1/01/2008 00:00 to 1/06/2011 23:00 \\
\hline Market Pairs & Final State of Market Integration \\
\hline SEM-EEX & 0.38 \\
\hline SEM-APX & 0.44 \\
\hline SEM-Belpex & 0.46 \\
\hline SEM-EXAA & 0.39 \\
\hline SEM-Elspot & 0.43 \\
\hline$* * * * *$ indicate significance at the 10,5 and 1\%-levels
\end{tabular}

The results from Table 6 show a large improvement in the final state of market integration coefficient for all market pairs after the inclusion of negative prices. The availability of more market information through prices might have resulted in such increase. However, the results are no longer significant at $(1,5$ or 10$) \%$ even though a higher degree of price convergence is indicated. Our results based on the existing dataset do not support the claims of policymakers that increasing renewable wholesale trade will lead to an increasingly integrated market for electricity in Europe. Negative prices, by definition, occur at low demand levels but high wind in-feed possibly from using unlimited supply bids leads to uncertainty and instability in the wholesale 
electricity trade. Nonetheless, the hypothesis needs to be tested with longer timeseries in the future.

In order to facilitate comparison and establish a benchmark case of market integration between SEM and other markets, we also calculated the market integration coefficients among the large, interconnected and mature electricity wholesale markets considered in this study. We considered all the market pairs with more than $90 \%$ price correlation as obtained from our correlation analysis. Table 7 illustrates the market integration coefficients between other established wholesale markets. Considering that interconnection currently just amounts to $4.7 \%$ of SEMs available generation capacity, our results also show the required level of interconnection in SEM to reach the integration level of other well established wholesale markets in Europe.

Table 7: Market integration coefficients among selected markets (log prices)

\begin{tabular}{|c|c|c|}
\hline \multicolumn{2}{|c|}{$\begin{array}{c}\text { Method: Maximum likelihood (Marquardt) } \\
\text { Sample: 1/01/2008 00:00 to 1/06/2011 } 23: 00\end{array}$} & $\begin{array}{c}\text { Required level of interconnection in SEM } \\
\text { (as percentage of total generation capacity) }\end{array}$ \\
\cline { 1 - 2 } Market Pairs & $\begin{array}{r}\text { Final State of Market } \\
\text { Integration }\end{array}$ & $20.1 \%$ \\
\hline APX-Belpex & $0.77 * * *$ & $16.3 \%$ \\
\hline EEX-APX & $0.66^{* * *}$ & $21.3 \%$ \\
\hline EXAA-APX & $0.86^{* * *}$ & $24.3 \%$ \\
\hline EXAA-EEX & $0.62 * * *$ & \\
\hline
\end{tabular}

$*, * *, * * *$ indicate significance at the 10,5 and $1 \%$-levels

The market integration coefficients among the selected markets are more than 50\% in all cases while being as high as $86 \%$ between EXAA and APX. Similarly, the strength of price relations between APX-Belpex, EEX-APX and EXAA-EEX stands at around $77 \%, 66 \%$ and $62 \%$ respectively. A high cross-border trade of electricity via interconnections combined with similarity in market structure, design, and governance are the likely explanatory factors resulting in a high market integration coefficient among these markets.

Based on the current level of market integration and interconnection capacity in SEM, we can infer that an increase to $20.1 \%$ of interconnector generation capacity from the current $4.7 \%$ level will raise the market integration coefficient between SEM and APX to 0.66 as currently exists between APX and Belpex. Ceteris paribus, this would 
imply a cost-savings (or consumer surplus) of about 248 million euros in SEM assuming that hourly wholesale prices in SEM reach the existing APX levels. Similarly, a $16.3 \%$ of interconnection capacity as of total generation capacity will increase the market integration coefficient between SEM and Belpex to 0.66 as currently prevails between EEX and APX. Allowing the average hourly wholesale prices in SEM to reach the Belpex levels would generate a cost-savings of 272 million euros, all other things remaining constant. It is desirable that the interconnection amounts to $25.8 \%$ of generation capacity to attain an integration coefficient of 0.62 between SEM and EEX as it currently exists between EXAA and EEX. This would generate a consumer surplus of about 333 million euros at the existing EEX price levels. Likewise, our results also show that a $21.3 \%$ of interconnection as a percentage of generation capacity will increase the market integration coefficient between SEM and APX to 0.86 as it currently stands between EXAA and APX. Similarly, assuming that average SEM wholesale prices reaches the Elspot levels with increased interconnections would create a welfare gain of about 514 million euros with all things remaining constant.

It is highly unlikely that market integration coefficient will reach unity as the price differences between two electricity wholesale markets cannot be zero due to transaction costs, transmission bottlenecks and other factors. However, the integration coefficient moving towards unity indicates that the price differences between the markets are diminishing. Hence, both markets are being increasingly competitive as increased competition implies the reduction in the average price levels. As the average wholesale prices in SEM are higher than other wholesale markets in Europe; significant potentials for wholesale price reductions exists through increased interconnections. Likewise, those markets with a high level of market integration can still pursue interconnections for security of supply and mitigating the potentials to market power abuse.

Thus, the proposals to expand the interconnections network through the East-West interconnector (Ireland-Wales) apart from the existing Ireland-Northern Ireland interconnector (Louth-Tandragee) and the existing 500 MW Northern IrelandScotland interconnector is certainly desirable. Moreover, it is essential that SEM is well connected with other large, mature and interconnected wholesale markets in 
Europe for further reduction in wholesale price levels and reduce unprecedented price volatility as suggested by economic theory. Experience from Elspot suggests that even though the region is dominated by seasonally varying hydro generation; price volatility is the lowest among all other wholesale markets at $14 \%$ because of increased cross-border trade of electricity via the power exchange (see Table A in Appendix). The time-varying path of the market integration coefficients between SEM and other markets observed in Figure A in Appendix show that the integration coefficient remained volatile and unstable over time and far from reaching unity which can primarily be attributed to various uncertainties (such as trading) and volatility associated with high liquidity in a newly established market. However, higher price volatility can be an inherent feature of a liberalized energy market where prices quickly adjust to market volatility and shocks.

\section{Conclusions and Policy Recommendations}

The aim of this paper was to examine the potential of interconnections in the allisland electricity wholesale market (SEM). A time-varying econometric technique based on Kalman filter algorithm was applied to determine the degree of market integration between SEM and other large, mature and interconnected wholesale electricity markets in Europe. Our results suggest that at the current state, market integration of SEM with other wholesale markets around Europe is low. High market liquidity in SEM has not necessarily meant higher market efficiency unlike Elspsot where the average hourly wholesale prices are the lowest. Thus, the all-island wholesale market cannot be deemed competitive.

Our results suggest that significant opportunities exist to close the gap between international price differences via increased interconnection. Reducing average hourly wholesale prices in SEM can engender significant welfare gains as also suggested by our results. Even though electricity in Ireland is mostly gas fired; increased crossborder electricity trade can have a downward pressure on domestic electricity prices in the island. Apart from benefits of price differences due to growing market size and economies of scale, low market integration would also imply connecting to 
international markets and benefit from increased security of supply and reduced price volatility as economic theory suggests.

While the average wholesale prices in SEM continue to remain high as compared to other markets; it is desirable that focus should be directed at alternative energy sources to reduce the reliance on gas-firing. The transition towards a low-carbon economy has meant that the Irish government has targeted to achieve 33\% of energy consumption from wind energy. However, our results based on the existing dataset however indicate that trading intermittent energy sources (such as wind) may not contribute towards market integration unless other complementary conditions such as storage, proper regulatory and market design framework, regulatory coordination etc. Although higher wholesale prices in SEM also raise the possibilities of market power abuse due to the presence of oligopolistic elements and lack of competition; interconnecting markets and increased trading of electricity on a level playing field (i.e. a common platform such as power exchange) can offset the problems of potential market power abuse and fuel competition in the wholesale market.

Thus, it is desirable that the process of interconnecting SEM to larger wholesale markets in Europe is intensified with investments in interconnector capacity and transmission networks. Equally important will be the appropriate regulatory framework and market design that incentivizes wholesale traders to actively engage in cross-border electricity trade and generate adequate investments in transmission infrastructure. 
EPRG No 1121

\section{Appendix:}

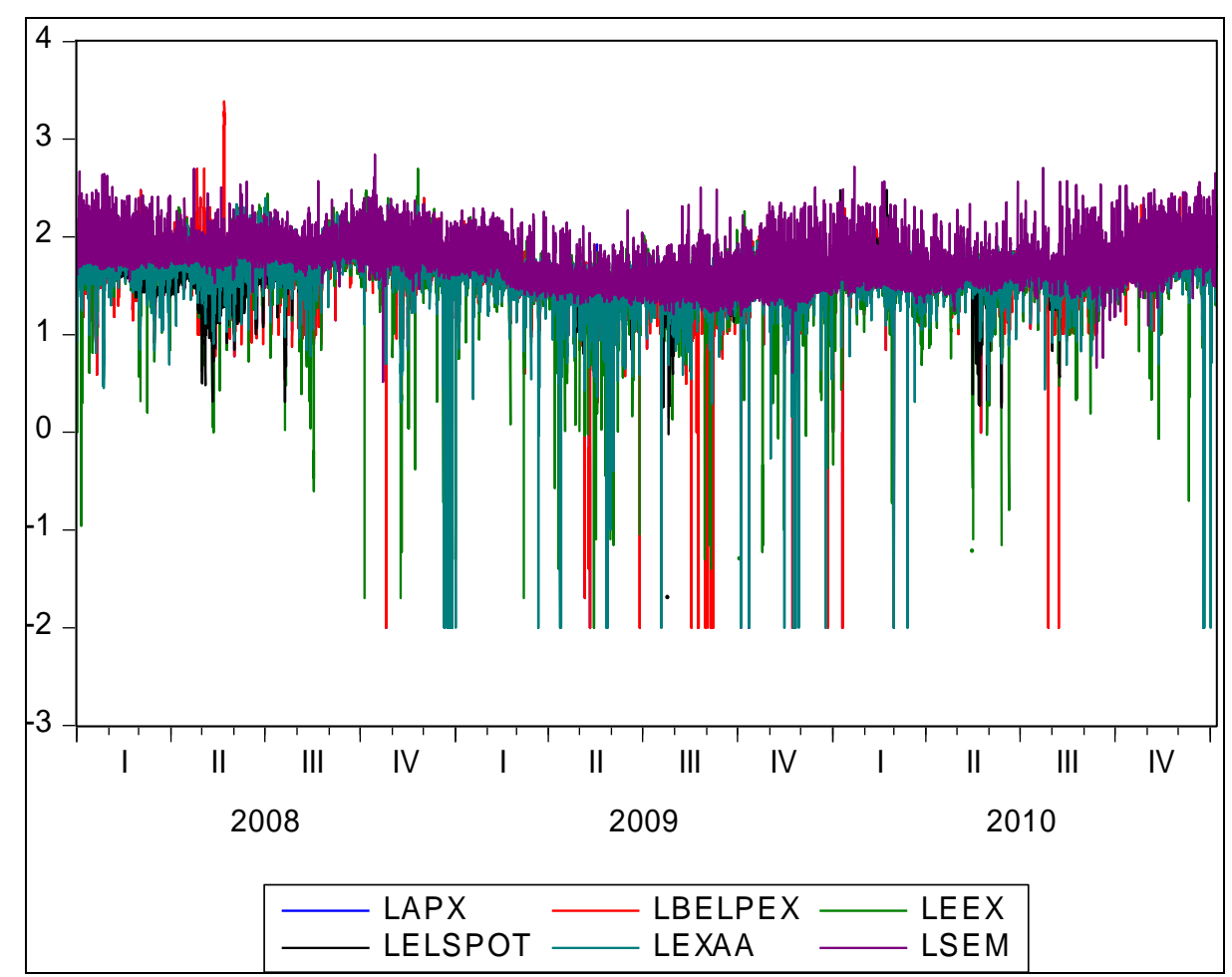

Fig A: Graphical representation of log transformed day-ahead hourly prices

\begin{tabular}{|l|c|c|c|c|c|c|}
\hline Eur / MWh & APX & BELPEX & EEX & ELSPOT & EXAA & SEM \\
\hline Mean & 52.181 & 51.487 & 49.702 & 44.469 & 50.110 & 59.336 \\
\hline Median & 47.710 & 47.000 & 45.980 & 42.850 & 46.070 & 51.777 \\
\hline Maximum & 500.000 & 500.00 & 494.260 & 300.030 & 248.270 & 695.785 \\
\hline Minimum & 0.010 & 0.010 & -500.020 & 0.000 & 0.010 & -26.025 \\
\hline Std. Dev. & 26.223 & 24.522 & 24.452 & 14.907 & 23.406 & 33.846 \\
\hline Skewness & 1.834 & 1.852 & 0.693 & 1.948 & 1.238 & 3.143 \\
\hline Kurtosis & 16.791 & 16.438 & 22.751 & 19.017 & 6.202 & 24.855 \\
\hline Observations & 26172 & 26206 & 26447 & 26445 & 26061 & 26448 \\
\hline
\end{tabular}

Table A: Descriptive statistics of raw prices

\begin{tabular}{|c|c|c|c|c|c|c|}
\hline & $A P X$ & $B E L P E X$ & $E E X$ & ELSPOT & EXAA & SEM \\
\hline$A P X$ & 1.000 & & & & & \\
\hline$B E L P E X$ & 0.963 & 1.000 & & & & \\
\hline$E E X$ & 0.883 & 0.855 & 1.000 & & & \\
\hline
\end{tabular}


EPRG No 1121

\begin{tabular}{|c|l|l|l|l|l|l|}
\hline ELSPOT & 0.398 & 0.397 & 0.422 & 1.000 & & \\
\hline EXAA & 0.923 & 0.893 & 0.927 & 0.435 & 1.000 & \\
\hline SEM & 0.588 & 0.560 & 0.564 & 0.275 & 0.602 & 1.000 \\
\hline
\end{tabular}

Table B: Correlation results of raw prices

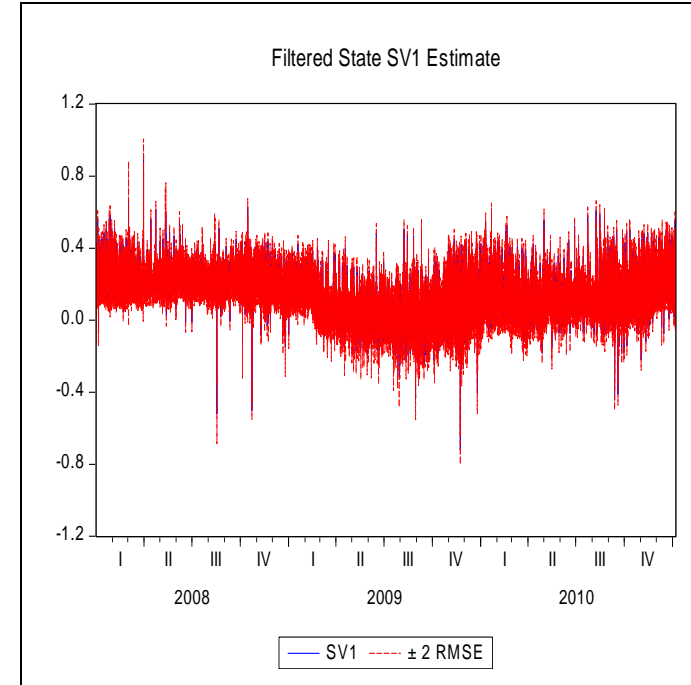

SEM-EEX

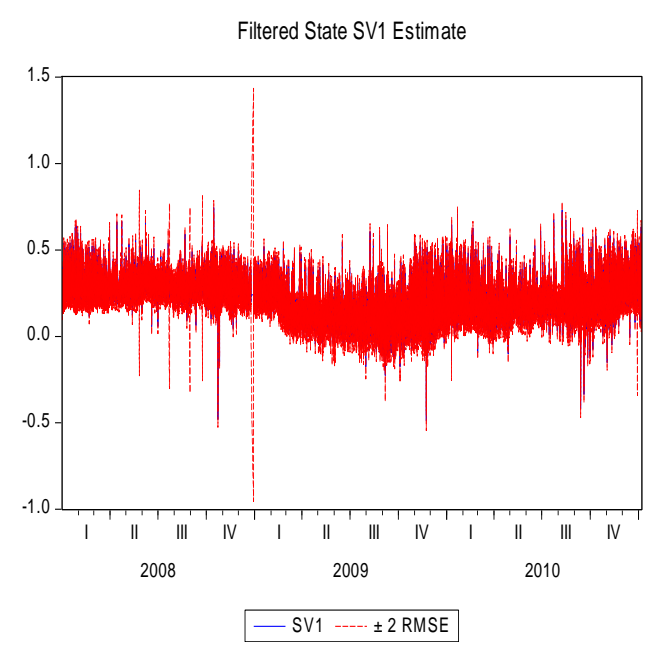

SEM-APX

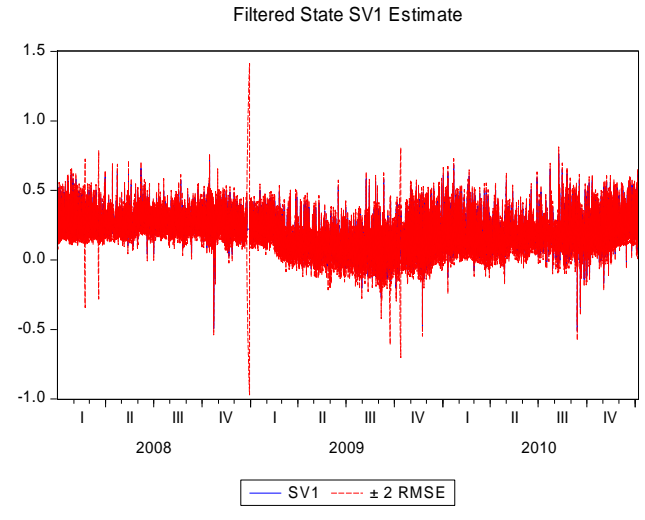

SEM-Belpex

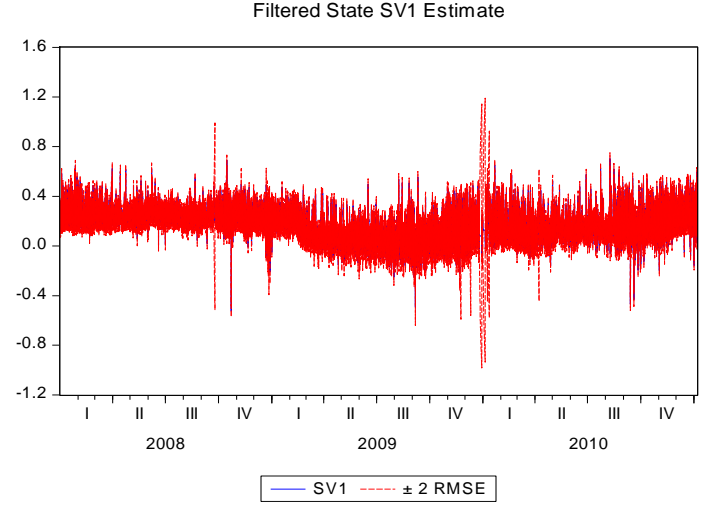

SEM-EXAA 
EPRG No 1121

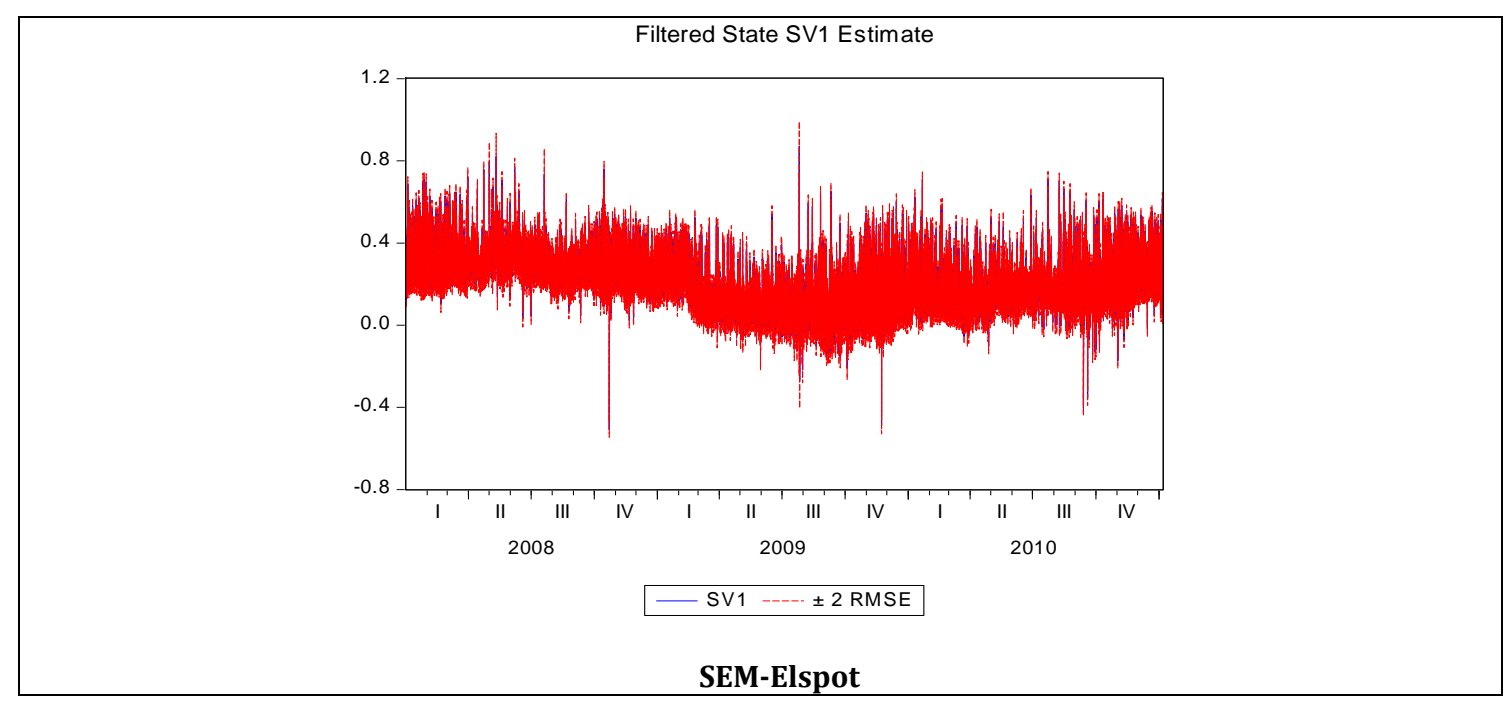

Figure A: Path of market integration coefficients for logarithmic prices 
EPRG No 1121

\section{References}

Armstrong, M. and Galli, A. (2005). Are Day-Ahead Prices for Electricity Converging in Continental Europe? An Exploratory Data Approach, Working paper, CERNA.

APX Endex (2011). APX Endex, APX Power Netherlands, Amsterdam, Netherlands.

Belpex (2011). The Belgian Power Exchange, Brussels, Belgium.

Bernard, A.B. and Durlauf, S. N. (1996). Intrepreting Tests of Convergence Hypothesis: Journal of Econometrics, Vol. 71(1-2), pp. 161-173.

Boiteaux, M. (1956). Sur la Gestion des Monopoles Publics Astreint a l'équilibre Budgétaire, Econometrica, Vol. 24, No. 1, pp. 22-40.

Bomhoff, E.J. (1992). Four Econometric Fashions and the Kalman Filter AlternativeA Simulation Study, Tilburg Center for Economic Research, Discussion Paper N0. 9227.

Bower, J. (2002). Seeking the Single European Electricity Market: Evidence from an Empirical Analysis of Wholesale Market Prices, Working Paper, Washington University in St. Louis, USA.

Boisseleau, F. (2004). The Role of Power Exchanges for the creation of a Single European Electricity Market: Market design and Market regulation, Delft University Press, Delft, Holland.

Brunekreeft, G. and Newbery, D.N. (2006). Should Merchant Transmission Investment be Subject to a Must-offer Provision?, Journal of Regulatory Economics , Vol. 30 (3), pp. 233-260.

Burdett, Kenneth, and Kenneth Judd (1983), Equilibrium Price Dispersion, Econometrica, Vol. 51 (4), pp. 955-69.

Charun, R. and Mornade, F. (1997). The Electric Sector in Chile: Main Aspects. In: Raineiri and Morande (Eds) (De) Regulation and Competition: The Electric Industry in Chile, ILADES/ Georgetown University.

Cuddington, J.T., and Z. Wang (2006), Assessing the Degree of Spot Market Integration for U.S. Natural Gas: Evidence from Daily Price Data, Journal of Regulatory Economics, Vol. 29, No. 2, pp. 195-210. 
Dickey, D. and Fuller, W. (1979). Distribution of the Estimators for Autoregressive Time Series with a Unit Root, Journal of the American Statistical Association, Vol. 74, pp. 427-431.

Engel, C. and Rogers, J. H. (2001). Violating the Law of One Price: Should We Make a Federal Case out of It?, Journal of Money, credit and Banking, Vol.33, pp. 1-15.

EEX (2011). European Energy Exchange, Leipzig, Germany.

EXAA (2011). Energy Exchange Austria, Wien, Austria.

Fama, Eugene (1970). Efficient Capital Markets: A Review of Theory and Empirical Work, Journal of Finance, Vol. 25(2), pp. 383-417.

Federico, G. (2007). Market Integration and Market Efficiency: The Case of $19^{\text {th }}$ Century Italy, Explorations in Economic History, Vo. 44, pp. 293-316.

Gebhardt, G. and Hoffler, F.(2010). How Competitive is Cross-Border Trade of Electricty, Theory and Evidence from European Electricity Markets, SFB/TR 15 Discussion Paper, 236.

Geneose, F; Geneose, M; and Wietschel, M. (2010). Occurrence of Negative Prices in the German Spot Market for Electricity and their Influence in the Balancing Power Markets and 7th International Conference on the European Energy Market, Conference Paper, pp. 1-6.

Green, R. (2008). Electricity Wholesale Markets: Designs now and in a Low carbon Future, The Energy Journal, Vol. 29, Special Issue, The Future of electricity: Papers in Honor of David Newberry, pp. 95-124.

Giesbertz, P. and Mulder, M. (2008). Economics of Interconnection: The Case of Northwest European Electricity Market, International Association of Energy Economics, Second Quarter.

Grossman, S. (1976). On the Efficiency of Competitive Stock Markets Where Traders Have Diverse Information, Journal of Finance, Vol. 31, pp. 573-585.

Hamilton, J. (1994). Time Series Analysis, Princeton University Press, New Jersey, USA.

Harvey, A.C. (1987), Applications of the Kalman Filter, Truman F. Bewley, (ed.): Advances in Econometrics, Fifth World Congress, Vol. 1, pp. 285-313. 
Hogan, W. (1997). A Market Power Model with Strategic Interaction in Electricity Networks, International Program on Privatization and regulatory Reform, Harvard Institute for International Development, July 15, Harvard University, USA.

Hotelling, H. (1939). The Relation of Prices to Marginal Costs in an Optimum System, Econometrica, Vol. 7, No.2, pp. 242-269.

Johansen, S. (1988), Statistical Analysis of Cointegration Vectors, Journal of Economic Dynamics and Control, Vol. 12, Nos. 2/3, pp. 231-254.

Johansen, S. (1991), Estimation and Hypothesis Testing of Cointegration Vectors in Gaussian Vector Autoregressive Models, Econometrica, Vol. 59, No. 6, pp. 15511580 .

Joseffson, L. G. (2009). Interview, President, European Electricity Industry Association, Eurelectric, June 23.

Joskow, P. (2003). Electricity Sector Restructuring and Competition: Lessons Learned, Cuadernos de Economia-Latin American Journal of Economics, Instituto de Economía, Pontificia Universidad Católica de Chile., Vol. 40(121), pp. 548-558.

Kalman, R.E. (1960). A New Approach to Linear Filtering and Prediction Problems, Transactions of the American Society of Mechanical Engineers, Journal of Basic Engineering, Series D, Vol. 82, No. 1, pp. 35-45.

King, M. and Cuc, M. (1996). Price Convergence in the North American Natural Gas Spot Markets, Energy Journal, Vol. 72, Issue, 1, pp. 17-26.

Klemperer, P. (2005). Bidding Markets, UK Competition Commission, Occasional Paper No. 1, pp. 1-41.

Kradelogiou, P. (1999). Agricultural Prices in Transition Economies: The Case of Bulgaria and Slovenia, Economics of Planning, Vil. 32, pp. 45-66.

Krugman, P.R. and Obstfeld, M. (2003). International Economics: Theory and Policy, 6th Edition, Pearson International Edition, 2007.

Kwiatkowski, D., P.C.B. Phillips, P. Schmidt and Y. Shin (1992), Testing the Null Hypothesis of Stationary against the Alternative of a Unit Root, Journal of Econometrics, Vol. 54, Nos. 1-3, pp. 159-178.

Lamont, O.A. and Thaler, R.H. (2003), Anomalies: The Law of One Price in Financial Markets, Journal of Economic Perspectives, Vol. 17 (Fall 2003), pp. 191202. 
Matsukawa, I. and Mulder, M.(2009). External Costs of Interconnection: The Case of NordNed, Austrian Association of Energy Economics, Conference Paper, 2009.

Nicolosi, M. (2010). Wind Power Integration and Power System Flexibility - An analysis of Extreme Events in Germany under the New Negative Price Regime, Energy Policy, Vol. 38(11), pp. 7257-7268.

Neumann, A., B. Silverstovs and C. von Hirschhausen (2006), Convergence of European Spot Market Prices for Natural Gas? A Real-Time Analysis of Market Integration Using the Kalman Filter, Applied Economics Letters, Vol. 13, No. 11, pp. 727-732.

Nord Pool Spot (2011). Nord Pool Spot, Elspot Market, Oslo, Norway.

Prazmoski, P.A. (2005). A Recursive Cointegration test Using Kalman Filter and its application to Fiscal Equilibrium in the Dominican Republic, Applied Economics Letters, Vol. 12, pp. 155-160

St. Aubyn, M. (1999). Convergence across Industrialized Countries (1890-1989): New Results Using Time-Series Methods, Empirical Economics, Vol. 24, pp. 23-44.

Stigler, G. J. (1969). The Theory of Price, Macmillan, London.

Stigler, G. J and Sherwin, R.A. (1985). The Extent of the Market, Journal of Law \& Economics, University of Chicago Press, vol. 28(3), pp. 555-85, October

Turvey, R. (2006). Interconnector Economics, Energy Policy, Vol. 34, pp. 1457-1472.

Ulbig, A. (2010). Volatility of Electricity Spot Market Prices, ETH-EPH Power System Laboratory, Power Market Lecture I, October.

UREGNI (2009). Single Electricity Market, Market Monitoring Unit, Market Update, Utility Regulator, December.

Werden, G. J. (1996). Identifying Market Power in Electric Generation, Public Utilities Fortnightly, February 15, 1996, p. 16.

Zachmann, G. (2008). Electricity Wholesale Market Prices in Europe: Convergence?, Energy Economics, Vol. 30, Issue 4, pp. 1659-1671. 
EPRG No 1121 